\title{
Pregnant patient presenting with headache and medulloblastoma and hydrocephalous: a case report
}

\author{
Swati Sharma, Archana Tripathi*
}

Department of Obstetrics \& Gynecology, Chirayu Medical College, Bhopal, Madhya Pradesh, India

Received: 12 November 2013

Accepted: 9 December 2013

\author{
*Correspondence: \\ Dr. Archana Tripathi, \\ E-mail: drarchtri09@gmail.com
}

(C) 2014 Sharma S et al. This is an open-access article distributed under the terms of the Creative Commons Attribution Non-Commercial License, which permits unrestricted non-commercial use, distribution, and reproduction in any medium, provided the original work is properly cited.

\begin{abstract}
Medulloblastoma, a primitive neuroectodermal tumor (PNET), is a second most brain tumor in children, accounting for about $20 \%$ of cases but is very rare in adults, $1 \%$ of all cancers in adults with only one third of cases occur in women and even less in pregnant women. It is primarily a cerebellar tumor. Symptoms include nausea, vomiting, loss of coordination, morning headache, seizures and personality changes. Treatment is surgical removal of tumor followed by radiotherapy. A grand-multipara presented in casualty with 30 weeks pregnancy \& complains of headache, visual disturbances \& disorientation. MRI findings were suggestive of medulloblastoma with hydrocephalus. Ventriculo-peritoneal shunting was done followed by termination of pregnancy. She delivered vaginally a live female child. After 15 days, her definitive neurosurgery was done. The uniqueness of this case is its rarity and symptoms of which are often masked by symptoms of pregnancy as syncope during pregnancy could be due to hypoglycemia, anxiety, orthostatic hypotension or cardiac causes.
\end{abstract}

Keywords: Medulloblastoma, Hydrocephalus, Pregnancy

\section{INTRODUCTION}

Medulloblastoma, a primitive neuroectodermal tumor (PNET), is a second most brain tumor in children, accounting for about $20 \%$ of cases but is very rare in adults ( $1 \%$ of all cancers in adults with only one third of cases occur in women and even less in pregnant women). ${ }^{1}$ It is primarily a cerebellar tumor. On a hematoxylin and eosin stain, it appears as a small blue cell tumour. Symptoms include nausea, vomiting, loss of coordination, morning headache, seizures and personality changes. Medulloblastomas can metastasize to placenta during pregnancy, to spine and might recur in subsequent pregnancy. Treatment is surgical removal of tumor followed by radiotherapy.

\section{CASE REPORT}

A previously healthy 28 years old female G5P4 presented in Gynae OPD in Chirayu Medical College with 30 weeks pregnancy and complaints of headache, visual disturbances, vomiting dizziness and decreased mentation since 20 days. She was subjected to various investigations after neurosurgical opinion. Her MRI showed space occupying lesion in cerebellar region with hydrocephalous which was most likely medulloblastoma. Her USG showed alive 30 weeks pregnancy with mild oligohydraminos. Neurosurgeon planned urgent ventriculo-peritoneal shunt to relieve her compressive symptoms. After discussion with relatives and with their consent, explaining them fetal and maternal morbidity, patient underwent shunt surgery and termination of pregnancy so that definitive surgery could be planned thereafter. She delivered alive female child uneventfully 
and child was discharged from NICU after 7days. After 15 days patient was posted for suboccipital craniotomy and surgical debulking. Patient is under close follow up and radiotherapy is planned.

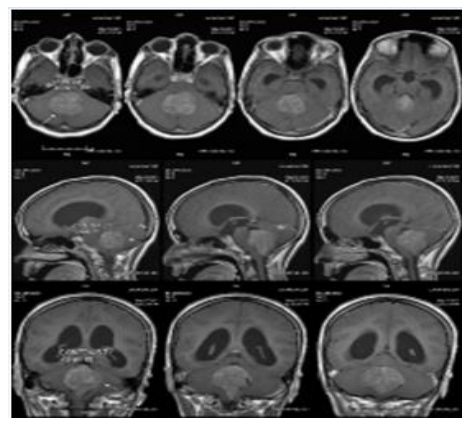

Figure 1: CT picture showing tumor in cerebellar region with hydrocephalus.

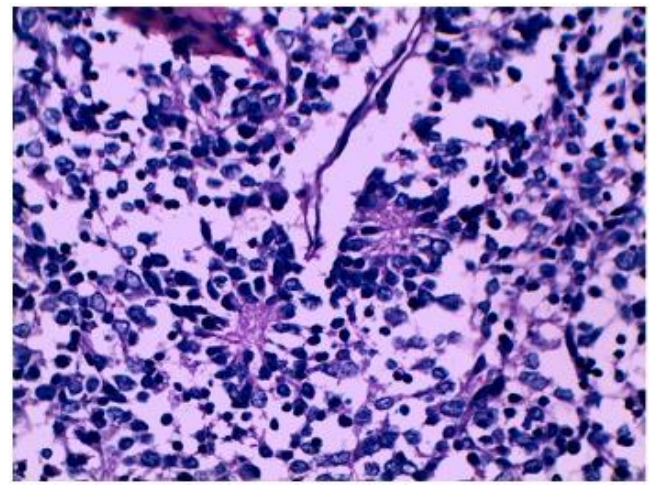

Figure 2: Histopathology picture showing blue cell tumor in rosettes.

\section{DISCUSSION}

Medulloblastoma is a cerebellar granule cell tumor, the most common cell type of cerebellum, and its robust proliferative capacity is thought to be regulated by sonic hedgehog pathway. $^{2}$ However, data suggests that cerebellar granule cells may be responsive to estrogen receptor stimulation. As such, pharmacologic blockade of estrogen receptors in cell cultures and xenograph models of medulloblastomas have shown to inhibit the migration and growth of medulloblastoma. ${ }^{3}$ These data suggest that a high levels of estrogen observed during pregnancy may be a contributing factor for this tumor in pregnancy. ${ }^{4}$ The uniqueness of this case is its rarity and symptoms are often masked by symptoms of pregnancy as syncope during pregnancy could be due to hypoglycemia, anxiety, orthostatic hypotension or cardiac causes. ${ }^{5}$ In addition, the radiological report and gross features of tumor may be mimicked by other tumors as astrocytomas and meningiomas. 6,7

Funding: No funding sources

Conflict of interest: None declared

Ethical approval: Not required

\section{REFERENCES}

1. Adult medulloblastoma. Holland - Frei cancer medicine. Hamilton, ON: BC Decker, 2003. Available at: http:/www.ncbi.nlm.nih.gov/bookshelf/br.fcgi?book =cmed6\&part=A19676. Accessed July 2010.

2. Oliver TG, Grasfeder LL, Carroll AL, Kaiser C, Gillingham CL, Lin SM et al. Transcriptional profiling of the sonic hedgehog response; a critical role for $\mathrm{N}$-myc in proliferation of neuronal precursors. Proc Natl Acad Sci. USA. 2003;100(12):7331-6.

3. Sasai K, Romer JT, Lee Y, Finkelstein D, Fuller C, Mckinnon PJ et al. Shh pathway is downregulated in cultured medulloblastoma cells: implications for preclinical studies. Cancer Res. 2006 Apr 15;66(8):4215-22.

4. Belcher SM, Ma X, Le HH. Blockade of estrogen receptors signaling inhibits growth and migration of medulloblastoma. Endocrinology. 2009;150(3):111221.

5. The American Pregnancy Association. Pregnancy and dizziness, 2007. Available at: http://www.americanpregnancy.org/pregnacyhealth/d izziness.html. Accessed July 2010.

6. Ismail K, Coakham HB, Walters JM. Intracranial meningioma with progesterone positive receptors in late pregnancy. Eur J Anaesthesiol. 1998;15(1):1069.

7. Morag R, Brenner B. Syncope: differential diagnosis \& workup. Emedicine, 2010. Available at: http;//emedicine.medscape.com/article/811669differential. Accessed 13 April 2011.

DOI: $10.5455 / 2320-1770 . i j r \operatorname{cog} 20140346$

Cite this article as: Sharma S, Tripathi A.

Pregnant patient presenting with headache and medulloblastoma and hydrocephalous: a case report. Int J Reprod Contracept Obstet Gynecol 2014;3:229-30. 